\title{
Determination of Lupeol, a Cytotoxic Compound Against SW620 Cells in the Extracts of Ha-Rak Recipe
}

\author{
Pathom Somwong ${ }^{1, *}$, Chomnapas Chuchote ${ }^{2}$
}

\section{Pathom Somwong ${ }^{1, *}$, Chomnapas Chuchote $^{2}$}

'Department of Pharmaceutical Chemistry, College of Pharmacy, Rangsit University, Pathumthani, THAILAND.

${ }^{2}$ Department of Pharmacognosy, College of Pharmacy, Rangsit University, Pathumthani, THAILAND.

\section{Correspondence}

\section{Pathom Somwong}

Assistant Professor, Department of Pharmaceutical Chemistry, College of Pharmacy, Rangsit University, 52/347, Paholyothin Rd., Muang, Pathumthani 12000, THAILAND.

Phone no: (+66)2-997-2222 ext.1424

E-mail: pathom.s@rsu.ac.th

\section{History}

- Submission Date: 02-09-2020;

- Review completed: 08-09-2020

- Accepted Date: 14-10-2020.

DOI : 10.5530/pj.2021.13.18

Article Available online

http://www.phcogj.com/v13/i1

\section{Copyright}

(C) 2021 Phcogj.Com. This is an openaccess article distributed under the terms of the Creative Commons Attribution 4.0 International license.

\begin{abstract}
Introduction: Ha-Rak is an herbal recipe that has been stated by Ministry of Public Health, Thailand to utilize as the herbal medicines for the treatment of fever. The recipe comprises the roots of five plants including Capparis micracantha, Clerodendrum indicum, Ficus racemosa, Harrisonia perforata and Tiliacora triandra as its ingredients. Methods: The extracts of Ha-Rak and its five herbal principles were evaluated for their potential on the cytotoxicity against SW620 cancer cell lines using the MTT assay and an active compound, lupeol which was found as a cytotoxic compound in the herbal ingredients of Ha-Rak was further determined. A chromatographic method for investigating that compound in the extracts was developed herein. The analytical method comprised a cholesterol-coated C18 column, a mixture of acetonitrile and methanol (70:30) with a flow rate of $2 \mathrm{~mL} / \mathrm{min}$, and a diode-array UV wavelength at 210 $\mathrm{nm}$ as a stationary phase, mobile phase, and detector, respectively. Results: The amount of lupeol in the extracts of Ha-Rak and the herbal principles, which possessed cytotoxicity against SW620 cell lines with the $I_{50}$ values of $30.10-212.24 \mu \mathrm{g} / \mathrm{mL}$ displayed variously in the range of $4.50-250.62 \mathrm{mg} / 100 \mathrm{~g}$. The difference of the contents among the extracts was noted significantly $(P<0.05)$. The correlation between the lupeol contents and their cytotoxic performances on the tested cell lines was observed in our investigation. Conclusion: Our findings demonstrated that Ha-Rak recipe contains a promising cytotoxic compound, lupeol and it will support the recipe to subject further pharmacological studies on anticancer activity. Key Words: Ha-Rak, Benchalokawichian, Lupeol, Cytotoxicity, Cancer cell lines, MTT.
\end{abstract}

\section{INTRODUCTION}

Ha-Rak (Benchalokawichian) is one of the famous Thai herbal recipes, which has been included in the National List of Essential Herbal Medicines of Thailand. The recipe contains the five herbal roots including Capparis micracantha DC., Clerodendrum indicum (L.) Kuntze, Ficus racemosa L., Harrisonia perforata (Blanco) Merr., and Tiliacora triandra (Colebr.) Diels, which are ground and mixed equally in a capsule formulary. This herbal recipe has been issued as an antipyretic drug $^{1}$ and its efficacy and safety in Thai traditional utilization were evaluated and clarified. ${ }^{2,3}$ Nevertheless, other biological activities of the recipe have been further investigated such as antiallergic ${ }^{4}$, antiinflammatory ${ }^{5}$, antimalarial ${ }^{6}$, antimicrobial ${ }^{7}$, and cytotoxic activities ${ }^{8}$, these several biological effects were consecutively reported to support its benefit for alternative medicinal uses. In our previous study, we isolated and identified the chemical constituents of $C$. indicum, one of the herbal principles of the recipe and we obtained lupeol, a cytotoxic triterpenoid compound that displayed potent cytotoxicity against human colon adenocarcinoma (SW620) cell lines with an $\mathrm{IC}_{50}$ value of $1.99 \mu \mathrm{mol} / \mathrm{L} .{ }^{9}$ Lupeol has been explored as a chemical constituent in diverse herbal plants. ${ }^{10} \mathrm{It}$ was extracted as a valuable active compound from F. racemosa as well as the other Ficus species ${ }^{11,12}$ and it was also found as a chemical constituent of H. perforata. ${ }^{13}$ According to the effective cytotoxic activities of lupeol against various cancer cells on multi-targeting pathways in previous reports, the compound has been suggested as a promising therapeutic and chemopreventive agent. ${ }^{14-17}$ Thus, there is an evidence for supporting lupeol as a chemical marker agent in this continuing study. The chromatographic method using high- performance liquid chromatography (HPLC) with photodiode array detection (DAD) was considered to apply as an analytical method in our ongoing study, it was developed and validated for the analysis of lupeol in the extracts of 12 marketed Ha-Rak recipe. ${ }^{18}$ Though there are some previous studies of the recipe that demonstrated its active compounds, which possessed antiallergic, anti-inflammatory, and antioxidative activities $^{4,5}$, a study that elaborated on the cytotoxic constituents that responded to the cytotoxic activity of the recipe has been limited. The investigation of the extracts of Ha-Rak recipe on cytotoxicity toward SW620 cancer cell lines was performed in this study using MTT assay and the $\mathrm{IC}_{50}$ values of the tested extracts were obtained to evaluate their cytotoxic performance for the preliminary anticancer study. In addition to that, the amount of lupeol in the extracts and the herbal principles of the recipe was also determined. The contents of lupeol in the extracts of the recipe that obtained from different samples were also compared and sequentially analyzed with a oneway analysis of variance (ANOVA). Hence, the aim of the present work is to indicate the presence of a cytotoxic compound in Ha-Rak recipe and the results would be used as supportive data for preliminary assessment on the anticancer property of the recipe. 


\section{MATERIALS AND METHODS}

\section{Materials and reagents}

The 12 marketed samples of Ha-Rak recipe, the herbal capsule preparations in Thailand were purchased from the traditional pharmacies in the month of October 2017. They were authenticated by comparing with genuine samples using the pharmacognostic methods that were described in a literature ${ }^{1}$ at the Department of Pharmacognosy, College of Pharmacy, Rangsit University, Thailand. The samples were numbered as 1-12. In addition, the raw plants that are the ingredients of the recipe were purchased and also authenticated in the same way. Lupeol (CAS no. 545-47-1) was supplied from Nanjing Spring \& Autumn Biological Engineering Co., Ltd., Nanjing, China. All analytical solvents used in the extraction, sample preparation and chromatography were procured from Honeywell Burdick \& Jackson ${ }^{\circ}$, Korea. The preparative process for analytical samples was performed by the solid-phase extraction (SPE) devices that containing the Bond Elut C18 cartridge $(100 \mathrm{mg}, 3.0 \mathrm{~mL})$ and VAC Elut-20 (16×100 mm), which belong to Agilent Technologies, Inc. and they were purchased from Thai Unique Co., Ltd. All disposable accessories used for HPLC in the analytical method development were procured from S.N.P. Scientific Co., Ltd., Thailand.

\section{Preparation of the sample solutions}

The powdered herbs of Ha-Rak (20 capsules) were mixed in a mortar and weighed accurately (5.0 g) into a thimble of Soxhlet apparatus (C. Gerhardt GmbH \& Co. KG, Germany). It was extracted in a Soxhlet extractor with $300 \mathrm{~mL}$ of methanol for $3 \mathrm{~h}$. The extract was evaporated to dryness in a rotary evaporator (Büchi Rotavapor R-114, Switzerland). The extract was reconstituted with small amounts of methanol and adjusted to $10 \mathrm{~mL}$ in a volumetric flask using methanol as a solvent. In addition, the powders of the five plants $(5.0 \mathrm{~g}$, each) that are the principles of the recipe were also extracted by the same method. They were prepared and adjusted to obtain $10 \mathrm{~mL}$ methanolic extracts as the sample solutions. Each sample solution $(3.0 \mathrm{~mL})$ was loaded onto a solid-phase extraction (SPE) cartridge $(\mathrm{C} 18,100 \mathrm{mg}, 3.0 \mathrm{~mL})$. The impurities in the sample were washed out with $3.0 \mathrm{~mL}$ of purified water and discarded. The analytes were subsequently eluted with the six cycles of $0.5 \mathrm{~mL}$ of methanol to collect $3.0 \mathrm{~mL}$ of the assay solution.

\section{Preparation of the standard solutions}

Lupeol (99\% purity, $12.5 \mathrm{mg}$ ) was dissolved in methanol and adjusted into the $25.0 \mathrm{~mL}$ volumetric flask to furnish a stock standard solution $(500 \mu \mathrm{g} / \mathrm{mL})$. A stock standard solution was pipetted $0.2,0.5,1.0,2.0$, 3.0 and $4.0 \mathrm{~mL}$ individually, transferred to the $10 \mathrm{~mL}$ volumetric flasks, and further adjusted by methanol to afford 10, 25, 50, 100, 150 and 200 $\mu \mathrm{g} / \mathrm{mL}$ of working standard solutions, as sequentially.

\section{Chromatographic conditions}

The HPLC system (Agilent Technologies, Inc., United States) was equipped with quaternary pump, degasser, autosampler, thermostatic column chamber and photodiode array detector (DAD) belonging in 1260 Infinity series. All devices were connected with the HewlettPackard computer, which was installed with Agilent OpenLAB software (HPLC 1260 online) for integrating the results from instruments. The assay solutions and working standard solutions were filtered through $0.45 \mu \mathrm{m}$ nylon membrane prior to analysis. Each filtered sample (20 $\mu \mathrm{L}$ ) was injected by automatic injector to a system that comprised a COSMOSIL (Cholester Waters type) packed column $(150 \mathrm{~mm} \times 4.6$ $\mathrm{mm}$ i.d., $5 \mu \mathrm{m})$ as a stationary phase and a mixture of acetonitrile and methanol (70:30) as a mobile phase. The flow rate of a system was conducted at $2.0 \mathrm{~mL} / \mathrm{min}$ and the column chamber was set at ambient temperature. The chromatograms of each sample were recorded in the range of DAD wavelength $(200-400 \mathrm{~nm})$ and the wavelength at 210 $\mathrm{nm}$ was selected to evaluate the peak data of lupeol. The analytical method for the determination of lupeol was validated following the requirements of International Conference on Harmonisation (ICH) guidelines and it was demonstrated in our recent report. ${ }^{18}$

\section{Quantification of lupeol in extracts}

Lupeol in the extracts of Ha-Rak recipe and the five raw herbal materials was examined using the Soxhlet extraction with SPE and the validated HPLC-DAD methods. The content of lupeol in the extracts was calculated by a linear regression equation, which was obtained from a calibration curve of lupeol standard solutions and expressed as milligrams of lupeol per 100 grams of dry powdered recipe. The marker contents were examined in triplicate and their SD values were also displayed and further submitted in the statistical analysis.

\section{Cytotoxic assay}

An in vitro cytotoxic assay of the herbal extracts against human colon carcinoma cell lines (SW620) was performed using the 3-(4,5-dimethyl-2-thiazolyl)-2,5-diphenyl-2-H-tetrazolium bromide (MTT) colorimetric method as described in a previous report. ${ }^{9}$ All extracts from the five plants of Ha-Rak recipe and its marketed products were dissolved in dimethylsulfoxide (DMSO) and diluted with culture medium to make a stock solution. A series of 2-fold dilutions of each stock solution was prepared for the assay and the final concentration of DMSO did not exceed $0.5 \%$ in each experiment. Dose response curves were plotted from 8 concentrations of a 2 -fold serial solution of each sample $(7.81,15.62,31.25,62.50,125,250,500$ and $1000 \mu \mathrm{g} / \mathrm{mL})$ against their percentage of cell survival in triplicate. The concentration of each extract that reduced the growth of a cancer cell line by $50 \%$ calculating from a curve was considered to report as the $50 \%$ inhibitory concentration ( $\mathrm{IC}_{50}$ value). Results of the MTT assay for tested samples were expressed in $\mu \mathrm{g} / \mathrm{mL}$. The cytotoxic activity of the herbal extracts was compared with that of lupeol, which was used as a positive control in this study.

\section{Statistical analysis}

A study of lupeol content in the herbal extracts was examined in triplicate and a mean \pm SD of each sample was also demonstrated. The cytotoxic investigation of the extracts on SW620 cell lines was carried out in triplicate and their $\mathrm{IC}_{50}$ values were also expressed as a mean \pm SD. The statistical comparisons between the groups of samples were carried out using a one-way analysis of variance (ANOVA) with Tukey's multiple comparison posthoc test (SPSS, SPSS Inc., Chicago, United States). A value of $P<0.05$ was determined for the statistical significance of all tested groups.

\section{RESULTS}

The investigation of lupeol in the extracts of Ha-Rak recipe, which were collected from 12 different sources (numbered as 1-12) along with the five herbal principles of the recipe was performed using the validated HPLC method and the lupeol content in each sample was calculated by using a linear regression equation that obtained from a calibration curve of lupeol standard solutions. The results of all analyzed extracts are summarized in Table 1 . The HPLC chromatograms of 12 extracts that demonstrated a signal of lupeol were overlaid, as shown in Figure 1.

The content of lupeol in 12 different samples of the recipe was observed in the ranges between $20.12 \pm 1.54$ and $61.61 \pm 6.47 \mathrm{mg} / 100 \mathrm{~g}$. These results demonstrate that there is no uniformity in regard to the amount of lupeol in these extracts. The highest yield of lupeol was found in sample 11, whereas the lowest content was observed in sample 1. Oneway ANOVA showed that samples 1-12 had significant differences in the lupeol contents $(P<0.0001, F=14.74, d f=11,24)$. Tukey's posthoc tests affirmed that the highest content of lupeol in sample 11 (61.61 
Table 1: Content of lupeol and cytotoxic activity of different Ha-Rak extracts.

\begin{tabular}{ccc}
\hline Sample & $\begin{array}{c}\text { Content of lupeol } \\
(\mathrm{mg} / 100 \mathrm{~g})\end{array}$ & $\mathrm{IC}_{50}(\mu \mathrm{g} / \mathrm{mL})$ \\
\hline 1 & $20.12 \pm 1.54$ & $47.10 \pm 0.88$ \\
2 & $39.31 \pm 6.19$ & $\mathrm{ND}$ \\
3 & $47.42 \pm 6.30$ & $\mathrm{ND}$ \\
4 & $43.01 \pm 7.18$ & $\mathrm{ND}$ \\
5 & $24.61 \pm 3.47$ & $\mathrm{ND}$ \\
6 & $27.75 \pm 4.48$ & $\mathrm{ND}$ \\
7 & $31.12 \pm 5.79$ & $\mathrm{ND}$ \\
8 & $26.79 \pm 2.39$ & $\mathrm{ND}$ \\
9 & $43.56 \pm 2.51$ & $42.60 \pm 0.91$ \\
10 & $34.02 \pm 8.51$ & $\mathrm{ND}$ \\
11 & $61.61 \pm 6.47$ & $37.30 \pm 0.77$ \\
12 & $33.94 \pm 1.61$ & $\mathrm{ND}$ \\
C. indicum & $4.50 \pm 0.21$ & $212.24 \pm 2.28$ \\
C. micracantha & $\mathrm{ND}$ & $\mathrm{ND}$ \\
F. racemosa & $250.62 \pm 3.80$ & $34.80 \pm 0.69$ \\
H. perforata & $\mathrm{ND}$ & $\mathrm{ND}$ \\
T. triandra & $7.94 \pm 0.14$ & $30.10 \pm 1.07$ \\
Lupeol (positive control) & - & $30.50 \pm 0.48$ \\
\hline
\end{tabular}

Values are shown as mean \pm standard deviation in three independent experiments, ND is represented the non-determined data.

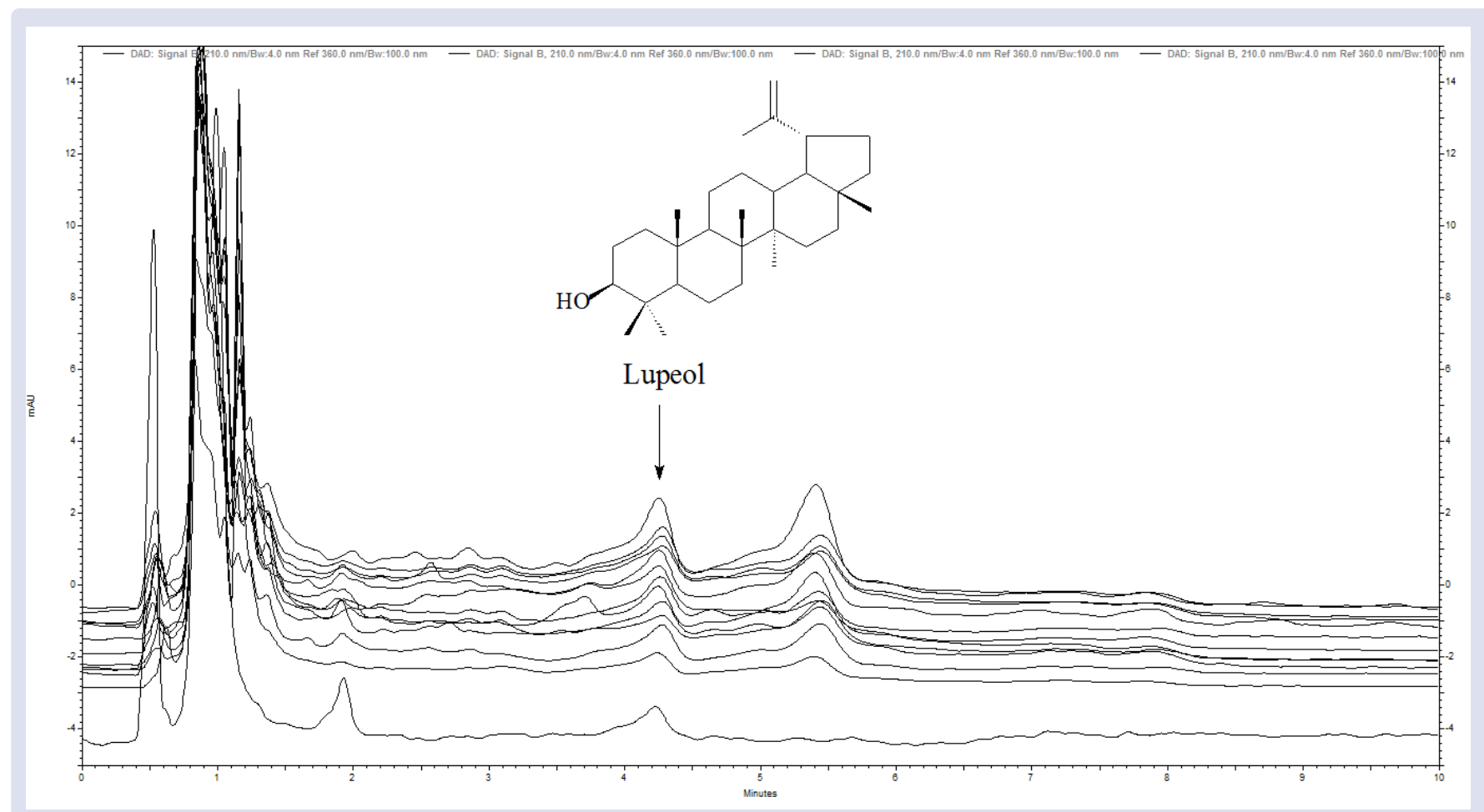

Figure 1: HPLC profile of lupeol in different Ha-Rak extracts, the signal of lupeol compound shows at 4.2 min in the overlay chromatograms of 12 marketed products (upper lines) and the standard chromatogram of authentic sample (bottom line).

$\pm 6.47 \mathrm{mg} / 100 \mathrm{~g})$ differed from all samples $(P<0.01$ to $P<0.001)$ except sample $3(47.42 \pm 6.30 \mathrm{mg} / 100 \mathrm{~g} ; P>0.05)$. Conversely, sample 1 that showed the lowest yield of lupeol $(20.12 \pm 1.54 \mathrm{mg} / 100 \mathrm{~g})$ had a significant content $(P<0.01$ to $P<0.001)$ as compared to samples 2,3 , 4, 9 and 11. Determination of the lupeol contents in the five raw plants of Ha-Rak recipe showed that $F$. racemosa possessed the highest yield of lupeol $(250.62 \pm 3.80 \mathrm{mg} / 100 \mathrm{~g})$. Its content was noted higher than the other plants and 12 extracted samples. On the other hand, C. indicum possessed the lowest lupeol content $(4.50 \pm 0.21 \mathrm{mg} / 100 \mathrm{~g})$, which was lower than any other contents that found in this study. Among five herbal principles, the amount of lupeol had not been observed in the extracts of $C$. micracantha and $H$. perforata, which were analyzed by the developed analytical method this time.

The extracts of 12 samples together with those of five herbal components of the recipe were selected to examine their effects on the inhibition of cancer cell growth. This study was carried out using the MTT assay against human colon adenocarcinoma (SW620) cell lines. Lupeol, a marker compound in the developed analytical method was used as a 
positive control. The cytotoxicity of the selected extracts toward that cancer cell lines was expressed as the $\mathrm{IC}_{50}$ values as displayed in Table 1 and the photomicrographs of cancer cells that were treated with the extracts at their active concentration values are shown in Figure 2. The extracts of samples 1, 9 and 11 that obtained from the different samples of the marketed recipe showed cytotoxic activity with the $\mathrm{IC}_{50}$ values of $47.10 \pm 0.88,42.60 \pm 0.91$ and $37.30 \pm 0.77 \mu \mathrm{g} / \mathrm{mL}$, respectively. Thus, the order of cytotoxic strength among them was $11>9>1$. Sample 11 had a large amount of lupeol, it also possessed a strong cytotoxic effect as compared to samples 1 and 9. On the other hand, a lower activity was observed in sample 1, which occupied a lupeol content lower than in the others. Observations indicated that the cytotoxicity of these extracts and their lupeol contents had a relationship. With respect to the five herbal principles, the extracts of C. indicum, F. racemosa and T. triandra demonstrated cytotoxicity with the $\mathrm{IC}_{50}$ values of $212.24 \pm 2.28,34.80$ \pm 0.69 and $30.10 \pm 1.07 \mu \mathrm{g} / \mathrm{mL}$, respectively. F. racemosa extract owned the highest lupeol content, it had an inhibitory effect toward cancer cell proliferation better than samples 1, 9 and 11. Whereas, $C$. indicum possessed the lowest lupeol content, its cytotoxicity was observed to be lower than that of all extracts in this investigation. Among these extracts, $T$. triandra expressed the best $\mathrm{IC}_{50}$ value as compared to the others, its activity was also observed stronger than a positive control. In addition, one-way ANOVA testing for the cytotoxic potency between the different extracted groups was performed. The difference on the cytotoxic effects among the extracted groups was noticed significantly $(P<0.05, F=3.96, d f=5,12)$. Posthoc tests indicated that the $\mathrm{IC}_{50}$ value of sample $1(47.10 \pm 0.88 \mu \mathrm{g} / \mathrm{mL})$ was significantly different from the
$\mathrm{IC}_{50}$ values of the extracts of T. triandra $(30.10 \pm 1.07 \mu \mathrm{g} / \mathrm{mL})$ and a positive control $(30.50 \pm 0.48 \mu \mathrm{g} / \mathrm{mL})(P<0.05)$, whereas no significant difference was observed in the $\mathrm{IC}_{50}$ value of sample $11(37.30 \pm 0.77 \mu \mathrm{g} /$ $\mathrm{mL}$ ) as compared to all tested extracts except for $C$. indicum.

\section{DISCUSSION}

The cytotoxicity against SW620 cancer cell lines of the extracts of Thai traditional Ha-Rak recipe and its herbal ingredients was examined to explore the potential of this herbal remedy for performing in-depth investigations on anticancer. Considering the chemical constituents of the herbal principles in the recipe, the cytotoxically active compounds such as pectolinarigenin and perforatic acid were isolated and their activities against cancer cell lines were also investigated in a recent report. ${ }^{19}$ However, the other promising cytotoxic agents have still been explored from the plants, which are the ingredients of the recipe. Lupeol, a cytotoxic compound that was determined as one of the active compounds in $C$. indicum ${ }^{9}$ was selected as an analytical marker herein, in order to examine the content in the recipe and also determine whether it was responsible for the cytotoxic activity against SW620 cell line. Lupeol, a natural lupane-type triterpenoid derivative has been reported to function as a cytotoxic compound by enhancement of reactive oxidative species and induction of cell apoptosis in various cancer cell line tests. ${ }^{20,21}$ In this study, the analyzed extracts demonstrated the lupeol contents varying from 20.12-61.61 $\mathrm{mg} / 100 \mathrm{~g}$ in $12 \mathrm{Ha}$-Rak marketed products and $4.50-250.62 \mathrm{mg} / 100 \mathrm{~g}$ in the herbal principles of the recipe. A positive correlation between the lupeol contents of different extracts of the recipe and their cytotoxic
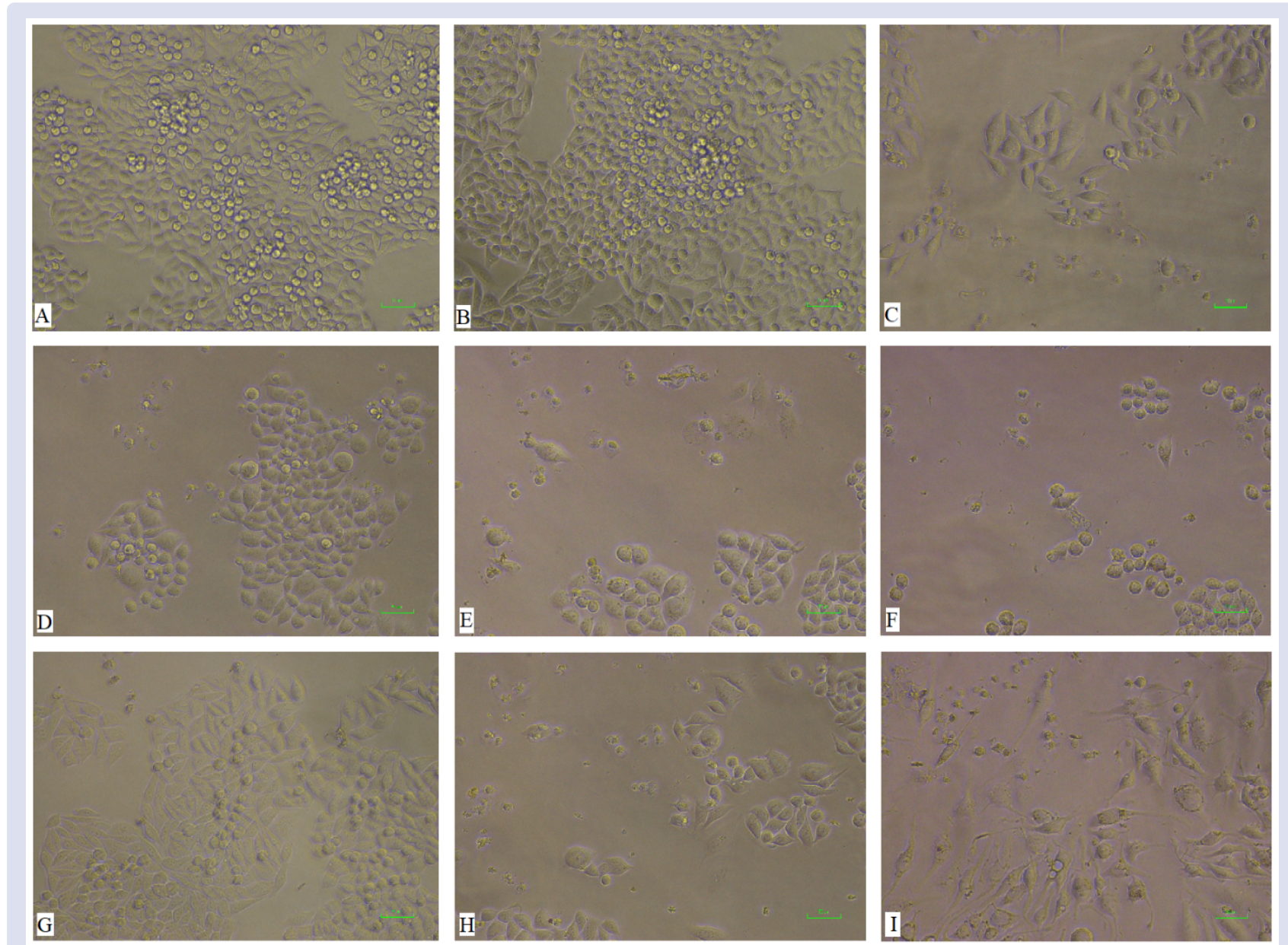

Figure 2: Photomicrographs of SW620 cells treated with the extracts at their active concentrations after $72 \mathrm{~h}$. (A) Culture medium; (B) normal control (DMSO); (C) lupeol; (D) sample 1; (E) sample 9; (F) sample 11; (G) C. indicum; (H) F. racemosa; (I) T. triandra. 
potency was noted in our investigations. The extract of sample 11 showed the best cytotoxicity as compared to the other samples of HaRak products, the activity of that extract seemed to have the relation with its lupeol content, which was observed to be higher than in the others. This relationship was also noticed in the extract of $F$. racemosa, the herbal principles of the recipe that contains the highest yield of lupeol, its cytotoxic activity was directly proportional to the lupeol content. These results corresponded to the previous Ficus reports that showed bioactivities involving their lupeol profiles. ${ }^{22-24}$ Although a direct correlation between the cytotoxic performance and lupeol content was observed in the extracted samples of $F$. racemosa and $C$. indicum, it was inverse in the extract of T. triandra, which possessed the highest cytotoxic potency in this study. The capability on cytotoxicity of T. triandra might correspond with prominent cytotoxic alkaloids, i.e. tiliacorinine, yanangcorinine and oxoanolobine, which are found as its chemical constituents and displayed powerful cytotoxicity in various cancer cell tests. ${ }^{25,26}$ Thus, these alkaloids might be responsible for the effect of T. triandra extract and explain why the cytotoxic activity of that plant was stronger than a positive control in this study.

Based on the cytotoxic effect of the extracts of Ha-Rak recipe, concerning the lupeol contents, the results indicated that the cytotoxicity of the tested extracts is correlated with the presence of lupeol in the recipe. Among the herbal ingredients, F. racemosa and T. triandra are two considerable active principles, which exhibited remarkable cytotoxicity toward human colon carcinoma cell lines in our study. Referring to the investigation of chemical compounds in medicinal plants, there are many regulating factors that would affect the yield of bioactive substances such as the geography of plant habitats, the season of the harvest and the environment of crops. ${ }^{27}$ In this way, the significant varying contents of lupeol among 12 samples of Ha-Rak recipe were distinguished in our investigation.

\section{CONCLUSION}

The developed chromatographic method can be effectively used for quantification of lupeol, a cytotoxic compound in the extracts of HaRak recipe and its herbal materials. Extracts from the recipe and its herbal principles including C. indicum, F. racemosa and T. triandra that contain significantly different contents of lupeol exhibited the cytotoxic activity toward SW620 cancer cell lines with varying degrees of $\mathrm{IC}_{50}$ values. The direct proportion between the contents of lupeol and their cytotoxic degrees was disclosed in all tested samples excluding $T$. triandra. This study indicates the presence of lupeol in Ha-Rak recipe and elaborates the performance of its extract in order to perform further in-depth studies on an anticancer property.

\section{ACKNOWLEDGEMENT}

Authors would like to thank the Research Institute of Rangsit University for the Grant (No.4/2560), which was funded to P. Somwong and the Institute of Biotechnology and Genetic Engineering, Chulalongkorn University for providing the cytotoxicity test.

\section{CONFLICTS OF INTEREST}

No conflicts of interest.

\section{REFERENCES}

1. Singharachai $C$, Palanuvej $C$, Kiyohara $H$, Yamada $H$, Ruangrungsi $N$. Pharmacognostic specification of five root species in Thai traditional medicine remedy: Ben-Cha-Lo-Ka-Wi-Chian. Pharmacogn J. 2011;3(21):1-11.

2. Jongchanapong $A$, Singharachai $C$, Palanuvej $C$, Ruangrungsi N, Towiwat $P$. Antipyretic and antinociceptive effects of Ben-Cha-Lo-Ka-Wi-Chian remedy. J Health Res. 2010;24(1):15-22.

3. Singharachai C, Palanuvej C, Kiyohara H, Yamada H, Ruangrungsi N. Safety evaluation of Thai traditional medicine remedy: Ben-Cha-Lo-Ka-Wi-Chian. J Health Res. 2011;25(2):83-90.
4. Juckmeta $T$, Thongdeeying $P$, Itharat $A$. Inhibitory effect on $\beta$-hexosaminidase release from RBL-2H3 cells of extracts and some pure constituents of Benchalokawichian, a Thai herbal remedy, used for allergic disorders. Evid Based Complement Alternat Med. 2014;2014: 828760. Available from: https:// www.hindawi.com/journals/ecam/2014/828760/

5. Juckmeta $T$, Itharat A. Anti-inflammatory and antioxidant activities of Thai traditional remedy called "Ya-ha-rak". J Health Res. 2012;26(4):205-10.

6. Nutmakul T, Pattanapanyasat K, Soonthornchareonnon N, Shiomi K, Mori M, Prathanturarug S. Antiplasmodial activities of a Thai traditional antipyretic formulation, Bencha-Loga-Wichian: A comparative study between the roots and their substitutes, the stems. J Ethnopharmacol. 2016;193:125-32.

7. Nuaeissara S, Kondo S, Itharat A. Antimicrobial activity of the extracts from Benchalokawichian remedy and its components. J Med Assoc Thai. 2011;94(Suppl 7):S172-7.

8. Juckmeta T, Ruangnoo S, Itharat A. Cytotoxic activities against two lung cancer cells of Thai antipyretic drug. Planta Med. 2016;82(S01):P976.

9. Somwong P, Suttisri R. Cytotoxic activity of the chemical constituents of Clerodendrum indicum and Clerodendrum villosum roots. J Integr Med. 2018;16(1):57-61.

10. Jager S, Trojan H, Kopp T, Laszczyk MN, Scheffler A. Pentacyclic triterpene distribution in various plants-rich sources for a new group of multi-potent plant extracts. Molecules. 2009;14(6):2016-31.

11. Lansky EP, Paavilainen HM, Pawlus AD, Newman RA. Ficus spp. (fig): Ethnobotany and potential as anticancer and anti-inflammatory agents. J Ethnopharmacol. 2008;119(2):195-213

12. Das AK, Mandal V, Mandal SC. Design of experiment approach for the process optimisation of microwave assisted extraction of lupeol from Ficus racemosa leaves using response surface methodology. Phytochem Anal. 2013;24(3):230-47.

13. Somsill P, Itthipanichpong C, Ruangrungsi N, Limpanasithikul W. Inhibitory effect of Harrisonia perforata root extract on macrophage activation. Thai $\mathrm{J}$ Pharmacol. 2010;32(1): 168-71.

14. Saleem M. Lupeol, a novel anti-inflammatory and anti-cancer dietary triterpene. Cancer Lett. 2009;285(2):109-15.

15. Siveen KS, Nguyen AH, Lee JH, Li F, Singh SS, Kumar AP, et al. Negative regulation of signal transducer and activator of transcription-3 signaling cascade by lupeol inhibits growth and induces apoptosis in hepatocellular carcinoma cells. Br J Cancer. 2014;111(7):1327-37.

16. Kangsamaksin T, Chaithongyot S, Wootthichairangsan C, Hanchaina $R$ Tangshewinsirikul C, Svasti J. Lupeol and stigmasterol suppress tumor angiogenesis and inhibit cholangiocarcinoma growth in mice via downregulation of tumor necrosis factor- $\alpha$. PLoS One. 2017 December;12(12):0189628.

17. Wang $Y$, Hong D, Qian $Y$, Tu $X$, Wang $K$, Yang $X$, et al. Lupeol inhibits growth and migration in two human colorectal cancer cell lines by suppression of Wnt- $\beta$ catenin pathway. Onco Targets Ther. 2018;11:7987-99.

18. Chuchote C, Somwong P. Similarity analysis of the chromatographic fingerprints of Thai herbal Ya-Ha-Rak remedy using HPLC. Interprof J Health Sci. 2019;17(2):55-63

19. Juckmeta T, Pipatrattanaseree W, Jaidee W, Dechayont B, Chunthorng-Orn $J$, Andersen RJ, et al. Cytotoxicity to five cancer cell lines of the respiratory tract system and anti-inflammatory activity of Thai traditional remedy. Nat Prod Commun. 2019 May;14(5):1-6.

20. Liu WK, Ho JC, Cheung FW, Liu BP, Ye WC, Che CT. Apoptotic activity of betulinic acid derivatives on murine melanoma B16 cell line. Eur J Pharmacol. 2004;498(1-3):71-8.

21. Chudzik M, Korzonek-Szlacheta I, Król W. Triterpenes as potentially cytotoxic compounds. Molecules. 2015;20(1):1610-25

22. Hanafi MM, Afzan A, Yaakob H, Aziz R, Sarmidi MR, Wolfender JL, et al. In vitro pro-apoptotic and anti-migratory effects of Ficus deltoidea L. plant extracts on the human prostate cancer cell lines PC3. Front Pharmacol. 2017 December;8:895.

23. Bopage NS, Gunaherath GK, Jayawardena KH, Wijeyaratne SC, Abeysekera AM, Somaratne S. Dual function of active constituents from bark of Ficus racemosa $L$ in wound healing. BMC Complement Altern Med. 2018 January;18(1):29.

24. Ogunlaja OO, Moodley R, Singh M, Baijnath H, Jonnalagadda SB. Cytotoxic activity of the bioactive principles from Ficus burtt-davyi. J Environ Sci Health B. $2018 ; 53(4): 261-75$

25. Sureram S, Senadeera SP, Hongmanee P, Mahidol C, Ruchirawat S, Kittakoop P. Antimycobacterial activity of bisbenzylisoquinoline alkaloids from Tiliacora triandra against multidrug-resistant isolates of Mycobacterium tuberculosis. Bioorganic Med Chem Lett. 2012;22(8):2902-5

26. Rattana S, Cushnie B, Taepongsorat L, Phadungkit M. Chemical constituents and in vitro anticancer activity of Tiliacora triandra leaves. Pharmacogn $\mathrm{J}$. 2016;8(1):1-3. Available from: http://phcogj.com

27. Khatoon S, Irshad S, Pandey MM, Rastogi S, Rawat AK. A validated HPTLC densitometric method for determination of lupeol, $\beta$-sitosterol and rotenone in Tephrosia purpurea: A Seasonal Study. J Chromatogr Sci. 2019;57(8):688-96. 


\section{GRAPHICAL ABSTRACT}

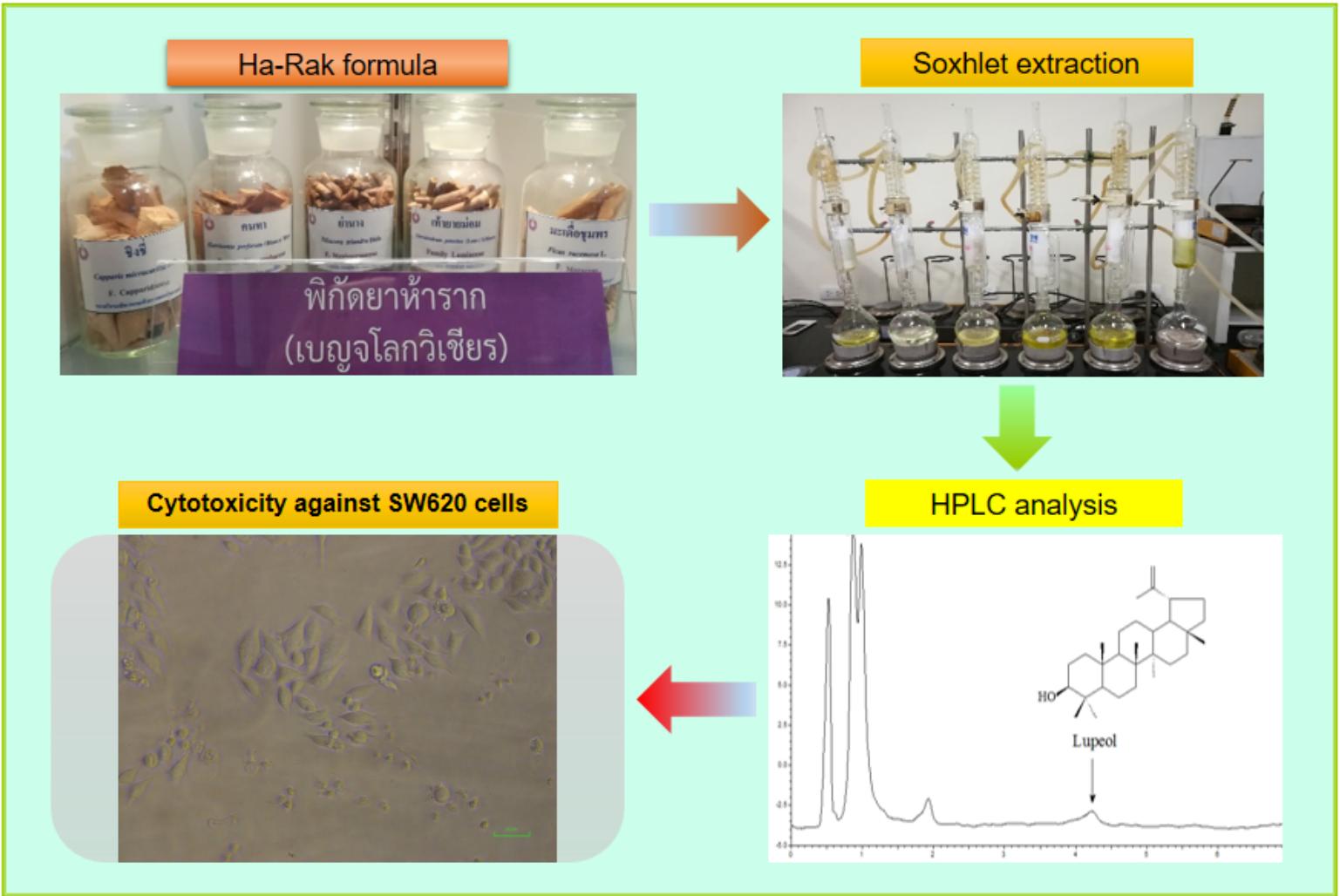

\section{ABOUT AUTHORS}

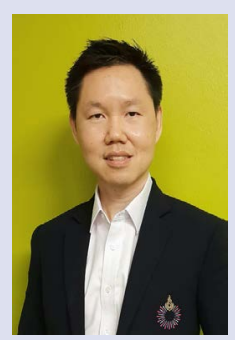

Dr. Pathom Somwong received his Ph.D. degree in Pharmacognosy from the Faculty of Pharmaceutical Sciences, Chulalongkorn University, Thailand. During his academic journey, he was granted a Royal Golden Jubilee Ph.D. Scholarship from Thailand Research Fund (TRF) to practice as a research student at Kobe Pharmaceutical University, Japan. Currently he is working as Assistant Professor at the Department of Pharmaceutical Chemistry, College of Pharmacy, Rangsit University, Thailand. His research interests are focused on Pharmacognosy and Phytochemical Analysis.

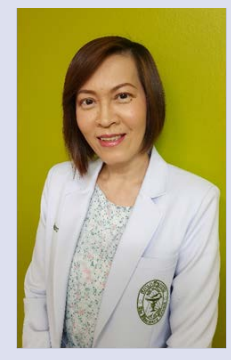

Ms. Chomnapas Chuchote received her Master of Pharmacy in Pharmacognosy from the Faculty of Pharmaceutical Sciences, Chulalongkorn University, Thailand. She is currently working as Assistant Professor at the Department of Pharmacognosy, College of Pharmacy, Rangsit University, Thailand. Her research field is focused on Pharmacognosy, Pharmacognostic Study and Herbal Pharmacy.

Cite this article: Somwong P, Chuchote C. Determination of Lupeol, a Cytotoxic Compound Against SW620 Cells in the Extracts of Ha-Rak Recipe. Pharmacog J. 2021;13(1): 133-8. 